Journal of Universal History Studies (JUHIS) • Vol. I • Issue 1 • 2018 • pp. 88-95

\title{
Sosyal Hayatın Önemli Unsurlarından: Kayseri Bağ Hayatı ve Hamam Külttürü ${ }^{1}$ Neslihan ALTUNCUOĞLU ${ }^{2}$ \\ Erciyes University, Assistant Professor, Department of History, Kayseri,Turkey \\ Received- Accepted: 07.11.2018-20.12.2018 \\ Research Article
}

$\ddot{O} \mathbf{z}$

Kayseri ilinin birçok yerinde bozkır iklim özellikleri hâkimdir. Burada yazlar sıcak ve kurak, kışlar soğuk ve kar yağı̧̧ı geçer. İklim özellikleri ve Kayseri'de kanalizasyon teşkilatının olmaması sttma hastalığının yaygınlaşmasına sebep olmuştur. Bu durum Kayserilileri yazları bağlara göçerek bu sezonu bağ evlerinde geçirmeye itmiştir. Haziran ayında başlayan bu yer değiştirme Kayseri'ye ait bir gelenektir. Bu gidilmeye "göç" denir. Kayseri'de geniş bağ alanları ve köklü bir bağcllk kültürü vardır. Bağcllğın ve yazları bağa göçme âdetinin Kayseri'de ne zaman başladığı bilinmese de, Kayseri halkı için bağlar ve bağcıllk büyük önem taşımış ve taşımaya da devam etmektedir.

Anahtar Kelimeler: Kayseri, Bağ Hayatı, Hamam Kültürü

\section{The Important Factors of Social Life: Kayseri's Vineyard Life and Turkish Bath Culture}

\begin{abstract}
In many parts of Kayseri province, steppe climate features prevail. Summers are hot and dry, winters are cold and snowy. Climatic characteristics, due to the lack of sewerage system in Kayseri, such as malaria disease common in the city, such as the Kayseri, summer in the vineyards to migrate to the vineyard this season has led to spend in the houses. This displacement, which starts in June, is a tradition belonging to Kayseri. This is called "migration. Kayseri has extensive vineyard areas and a long-standing culture of viticulture. Although it is not known when viniculture and summer labor began in Kayseri, vineyards and vineyards for the people of Kayseri are of great importance and continue to carry.
\end{abstract}

Key Words: Kayseri, Vineyard Life, Turkish Bath Culture

\footnotetext{
${ }^{1} \mathrm{Bu}$ çalışma Neslihan Altuncuoğlu'nun Erciyes Üniversitesi Sosyal Bilimler Enstitüsü’nde kabul edilen “Türk Kadınının Sosyo-Ekonomik ve Kültürel Hayata Katılımı (Kayseri Örneği:1923-1950)" adlı Yüksek Lisans tezinden üretilmiştir. 2 altuncuoglu@erciyes.edu.tr, ORCID: 0000-0002-3244-5077, This article is analyzed by two revievers and it is screened for the resembalance rate by the editor. (Bu makale iki hakem tarafından incelenmiş ve editör tarafından benzerlik oranı taramasından geçirilmiştir)
} 
Sosyal Hayatın Önemli Unsurlarından: Kayseri Bağ Hayatı ve Hamam Kültürü/Neslihan

ALTUNCUOĞLU

\section{Kayseri Bağ Hayat//Göç}

Bağcllk, memleketimizin türlü bölgelerinde önemli yer tutar. Bunlar arasında yer yer bağa göçme adı altında yazın bağ ve bahçelere geçici olarak taşınmalar olur. Hatta bazı bölgelerimizde bu taşınma geniş ölçüde meydana gelmektedir. Köy, kasaba yahut bir şehir halkının çoğunun, bir müddet için, yer değiştirdiği görülür. Birbirinden farklı müddet içinde süren ve çeşitli tarzlarda beliren bu bağ göçlerinin, türlü bölgelerde ayrı ayrı sebepleri vardır. Pek çeşitli olan bu sebepleri, ekonomi, sağlık yönlerinden ve her ikisinin birlikteki etkileri halinde göz önüne almak, bunlara bir de gelenekleşmeyi katmak mümkündür (İzbırak, 1947, s. 401-418). Anadolu'nun önemli bir tarih, kültür, ticaret merkezi olan Kayseri'de; iklim, malzeme, yaşam kültürü ve bölge faktörlerine bağlı olarak şekillenen evler, kendine özgü bir mimariye sahiptir. Özellikle Osmanlı döneminde gelişen sivil mimari içerisinde evlerin büyük bir çoğunluk ve önem arz ettiği görülmektedir. Kayseri'de azınlık gruplar genellikle ticaretle uğraşmışlar ve varlık içinde yaşamışlardır. Bu gruplar Germir, Talas, Tavlusun, Endürlük gibi merkezlerde görkemli ve büyük evler yapmışlardır (Tali, 2008, s. 165-185). Bă̆ evleriyle özel bir yere sahip olan Kayseri'de Hristiyan nüfus konut mimarisinde özellikle 16. yüzyıldan itibaren ön plana çıkmaya başlamış, sınırlı da olsa sivil mimaride etkili olmuştur (Tali, 2005, s. 61-85).

Kayseri bağ işi başı başına yazmaya, incelenmeye eşdeğer bir yaşantıdır. Haziran ayında başlayan bu yer değiştirme Kayseri'ye ait bir gelenektir. Kayseri şehri dar sokaklardan, kolay isınsın diye az sayıda küçük pencereli, odalı, bahçe yeşilliği az olan bitişik evlerden mürekkeptir. Sıcaklar başladı mı kışın çamuru toza dönüşür. Karpuz, kavun, üzüm vs. meyvelerin bollaştığı zaman karasinekler çoğalır. Sıcak, sinek, saman ve toz, adama ‘Aman Allah' dedirtir. 1950’li yıllarda Merhum Belediye Başkanı Osman Kavuncu bulut halinde inip kalkan cadde ve evleri kaplayan karasinekle mücadeleyi yapmakta zorlanmış, 'öldürülmüş bir kilo sinek getirene şu kadar para verilecektir' diye ilanlar yayınlamıştır. Enteresan bulunan bu ilanlar Avrupa gazete ve televizyon haberlerinde yer almıştır. İşte bütün bu iç bunaltıcı hallerden kurtulmak için şehre uzaklığı en az üç ve en çok on beş kilometre olan bağlara gidilirdi. Bu gidilmeye "göç" denir (Yeğenoğlu, 2011, s. 27-28). Bahar gelmesiyle bağ işleri başlar; bağın bellenmesi, çubukların ve ağaçların budanması gübrelenmesi su olmadığı zamanlarda kuyuların doldurulması bağ için önde gelen işlerdir. Bu işleri çoğunlukla evin erkeği üslenmiştir (Bozkurt, 2011).

Kadınlar ev işlerini yapar; şehirdeki evleri toplamak, naftalinlemek, halıların temizlenmesi, bağa gidecek eşyaların ve yiyeceklerin hazırlanması kadının işidir. Bağda evlerin temizlenmesi, serilmesi yine kadının görevidir (Yeğenoğlu, 2011, s. 27-28). Bağa taşınmak ayn bir zorluktur. Eski zamanlarda bağa göçmek için atlar ve eşekler kullanılmıştır (Ulusoy, 2011).

Kadın bağa atın ya da eșeğin üzerinde gider. 3-4 ay bağda kalır bu süre zarfinda zorunlu bir hal 
Journal of Universal History Studies (JUHIS) • Vol. I • Issue 1 • 2018 • pp. 88-95

olmadıkça şehre gelinmez, ne zaman ki havalar soğur göç zamanı başlar kadın yine atın veya eşeğin üzerinde şehre gelir (Baydoğan, 2011).

Evin kıymetli eşyası halı, kilim, yünlüler daha ziyade kışlık giyim, yükte hafif pahada ağır bakır eşya evin az güneş gören fakat rutubetli olmayan bir yerine üst üste bir mikâp şeklinde yerleştirilir ve her tarafi bir örtüyle iyice kapatılır ve buna Mafraş (Mafraç) denir. Naftalin konularak güve ve diğer haşaratın tahribinden korunur. Ev halkı mafraşları kuruldu mu, bağa göçmeye hazır demektir. 'Bağa ne vakit göçüyorsunuz?' sorusuna 'Mafraş’ımız kuruldu/kayıldı, artık hazırız, akşama sabaha” denilerek cevap verilir (Yeğenoğlu, 2011, s. 28).

Evin hanımı ve yardımcıları halka, kete, peksimet, kar suyuyla özenip bulgur pilavının yanında içilen ekşi pekmez, kuru çemen, eğe kemiğinden yapılmış fakat çemene yatırılmamış pastırma v.s. hazırlar. Ev sahibinin tembihlediği sayıda eșekler sabah erkenden kapı önüne getirilir. Yokuşu az olan bağ evlerine demirden yapılmış, çember tekerlekli “tatar arabası” denilen, bir veya iki atın çektiği arabalarla da göçülür. Bakırların hemen hepsi döğme bakırdandır. Bağa giderken hepsi kalaylanır. Şehir evinden bağ evine ulaşmak üç, dört saat içine sığdırılır (Yeğenoğlu, 2011, s. 32).

Bağ yaşantısı kadın için ayrı bir zorluktur, güç yanlarından biri su ile ilgilidir; suya bağımlı olan her faaliyet için kuyudan su çekip bir yere depolama gereği, ev işlerinden sorumlu olan kadınların yaşamlarını oldukça güçleştirmiştir. Helâların, örtme ve köşklerin her gün yıkanması; yemek hazırlığı, odun ocağında kullanılan tencerelerin isli bulaşığı ve abdest alma, yıkanma gibi her türlü temizlik için su gerekmektedir. Avludaki bitki ve çiçeklerin, ahırdaki hayvanların da suya ihtiyacı vardır (İmamoğlu, 2011, s. 107). Geleneksel bağ hayatının güçlüklerine gögüs gerenlerin başında gelinler gelir. Akşamları yatmadan önce bazlama, yağlama hamuru yoğurmak; sabah namazına kalkan kaynatanın (kayınpederin/kayınbabanın) eline su dökmek; evi, avluyu süpürmek; yemeğe yardım etmek; bağdaki meyveye, üzüme yetişmek... Tüm bu işleri büyük bir gayret ve sevecenlikle yapan bazı gelinlerin saçı başı dağılır, üstü kirlenir, el ve ayak ciltleri bozulur, bakımsız bir görünüm alırlardı. Kayseri'de kullanılan 'bağ gelini” deyimi, bu tür işleri gören; kır hayatına uyum sağlamış; okuması yazması az veya hiç olmayan, orta veya alt-orta sosyo-ekonomik düzeydeki ailelerin gelinlerine takılmış bir isimdir. Bu deyim, büyük olasılıkla üst veya orta-üst sosyo-ekonomik düzeydeki Kayseri ailelerinin kendi evlerinin işlerini gören gelinlere ve bağ yaşamına yönelttiği, ilginç, iğneleliyici ve biraz acımasız bir eleştiridir. Aynı zamanda da bağ yaşamıyla ilgili çelişkili bir değerlendirme olarak görülebilir (İmamoğlu, 2011, s. 109).

Yemek ve ekmek pişirmek için bahçede kurumuş olan ağaç dalları, gilamada; bazen de ot, firez (dallı ot), tezek ve saçma kullanılırdı. Ocaklar çabuk alev alan kevenlerle tutuşturulur, pişirilecek yemek veya ekmeğe uygun yakıtla beslenirdi. Yemekler odun ateşinde, güveç ve hamur tatlıları tezek ateşinde pişirilirdi. Sac üstünde pişirilen ekmek çeşitleri ve hamur işleri için gilamada ve ot kullanılırdı. Bağlarda firın olmaması ve geleneksel Kayseri yaşamında çarşıdan ekmek getirmenin ayıp sayılması, kadınlara bir de hamur yoğurma ve ekmek pişirme görevini yüklerdi. Bu nedenle ekmek pişirme ve hamur işleri 
Sosyal Hayatın Önemli Unsurlarından: Kayseri Bağ Hayatı ve Hamam Kültürü/Neslihan ALTUNCUOĞLU

bağlarda önemli bir yer tutar; günaşırı ya da üç günde bir bazlama veya yufka, üç dört günde bir de yağlama veya çörekler pişirilirdi. Bazlamalar içli veya içsiz olur, çöreklerin içine kıyma, peynir, soğan veya "hakırdak"( kuyruk yağını kurusu) konurdu. Yağlı hamurdan yapılan katmer ve evde ekmek bittiği zaman, hamurunun ekşimesini beklemeden yapılan, saçta veya tandırda pişirilen "bezdirmeç" adlı çörek de ekmek yerine geçerdi. Çeşit çeşit mant, su böreği; ocakta pişirilebilen tatllardan nevzine ve kesme kadayif gibi geleneksel Kayseri yemekleri yenirdi. Pişirme işi için çocuklar yakacak getirir, varsa evdeki büyükanne, yoksa anne veya deneyimli biri pişirme işini üstlenirdi. Odun ateşinde pişirilen yemeğin isinden ve dumanından kurtulmak için 1950'li ylllarda Kayseri'de büyük bir gürültüyle çalışan ve gazyağ yakan ocaklar kullanılmaya başlanmış, yemek pişirme işi biraz kolaylaşmıştır (İmamoğlu, 2011, s. 109).

Bağdaki binalar doğaya fazlasıyla açık olduğu için, kent evlerinde aranan ince temizlik bağ evlerinde yoktur. Toprak, kum veya taş olan avlu ve döşemeler her gün süpürülür veya yikanır. Eve çekidüzen verildikten sonra diğer işlere geçilir. Evlerde fazla eşya ve aksesuar kullanılmaması; pencerelerin camsız, yerlerin halı kilimsiz (çıllak), duvarların zarsız, dolapların kapaksız olmasi; silme, yıkama, toz alma gibi ince ev işlerini azaltmıştr. Ancak evlerdeki kapalı mekân sayısı azdır. Bu nedenle, kolay temizlenip toparlanan evler çabuk da dağılmıştr. Bu nedenle günde birkaç kez yeniden düzenleme yapmayı gerektirmiştir (İmamoğlu, 2001, s. 109).

Bir hafta on gün içinde (niyetteki, yani sınırları belli semtteki) komşular gezilmeye başlanır. $\mathrm{Bu}$ gezmeler öyle yoğunlaşır ki sabah saat on on bir arası kuşluk, on bir on iki arası öğle, on üçten sonra öğle vakti gezmesi diye adlandırlır. Bu saatlerde bir araya gelinir. Hanımların gezmesinde güncel konular konuşulur eleştirilir daha ziyade birbirlerini görmedikleri zaman da cereyan eden olaylar havadis olarak nakledilir. Misafirlere henüz meyveler olgunlaşmamışsa çay ve kahveden sonra yöreye mahsus çocuk yumruğu büyüklüğündeki Paşa Şekeri ikram edilir(Yeğenoğlu, 2011, s. 32-33).

Bağlar, ailelerin kışın tüketecekleri yiyeceklerin büyük bir bölümünü hazrladıkları yerlerdi. Meyve ve sebzelerle ilgili kış hazırllkları haziranda başlar, göç̧ünceye kadar sürerdi. Bağ ve bahçede yetiştirilen meyve ve sebzeler yaz boyunca kurutulur; pestili, reçeli, marmeladı veya konservesi yapılır, kente gönderilirdi. En yoğun iş bağ bozumundan sonra yapıllırdı (İmamoğlu, 2011, s. 109). Küfeler, sepetler hazırlanır. Şire ilanı ve şire kazanı elden geçer. Bağı büyük, yani üzümü çok olanların avlusunda yekpare taştan oyulmuş şirenin akacağı çörteni bulunan, elli altmış santim yerden yukariya yerleştirilmiş 'Şiraneler' vardır (Yeğenoğlu, 2011, s. 33). Bağ bozulurken kara (siyah) ve beyaz üzümün ayrı ayrı kesilmesine dikkat edilir. Çünkü yapllacak pekmezin kalitesinde üzümün rengi rol oynar. Kesilen üzümler şiraneye yakın serilmiş hasırlar üzerine serilir veya yığlır. Güçlü, kuvvetli bir genç hanım veya oğlan diz kapaklarına kadar temizlenmiş ayakları ile veyahut sırf ezmek için kullanılan bir çizme ile şiranedeki üzümü ezer. Şirane çörteninin altındaki büyük bakır kazan dolunca alınır ve bir yenisi konularak ezilme devam edilir. Lüzumu kadar pekmez toprağa atılır. Bu toprak önce bulunduğu mahalden eşilir. İyice 
Journal of Universal History Studies (JUHIS) • Vol. I • Issue 1 • 2018 • pp. 88-95

kurutulur, şayet pekmez toprağını bulamazsa çok temiz mangal kömürü külü de kullanılabilir(Yeğenoğlu, 2011, s. 38). Pekmez kaynarken üzüm pestilleri, köfteler yapılır; daha önceden iplere dizilmiş olan badem ve cevizlerden tatlı sucuk yapmak için karışımlar hazırlanırdı. Tepsi, sini veya bezlere dökülen pestil ve köfteler, toz almayacak yerlere yerleştirilir; bulamaçlara batırlan badem ve cevizler dışarıya asılır, kurumaya bırakılırdı (İmamoğlu, 2001, s. 110). Henüz güneş sıcaklığını kaybetmemiştir. Aş Makarna kesmenin zamanı gelmiştir. Bir gün evvel aş makarnası kesilecek evin hanımları hamuru hazırlar(Yeğenoğlu, 2011, s. 38). Yakın komşuların ve ev halkının elbirliği ile yapılan bu iş için herkes seferber olur, iki üç gün boyunca köşkler ve odalar hamur leğenleri, hamur tahtaları ve üzerlerine erişterelerin serildiği bezay örtülerle dolardı. Böyle günlerde bazen kadın aş̧̧llar da yardıma çağrllir, eriştemakarna kesenlerin yükü azalthlırd. Her durumda ev sahipleri bütün gün boyunca komşulara ve iş görenlere hizmet eder, onlara yemek hazırlar, ikramda bulunurdu. Sebze yetişen bağlarda patlıcan, biber, kabak, fasulye, bezelye, nane kurutulur; bağda yetişiyorsa bağdan, yoksa Argincik'tan gelen kelekle turşular kurulurdu(İmamoğlu, 2001, s. 111).

Bağdan en son toplanan şey gilâburu'dur. Küplere konacak üstü su ile doldurulacak, kışın yenecek veyahut ezilip suyu içilecektir. Okul açılmadan bir iki gün evvel şehre daimi inilecektir. Bağ evleri Niyetin (Semtin) bekçisine brrakılacaktır. Ev temizliği bitince, "Mafraş" bozulur. Yazın hazırlanan el emeği bağ semeresi gidalar Tokana-Ambar-Zerzembiye (Zerzemi) yerleştirilir. Ev hanımlarnın yoğun işi henüz bitmemiştir. Evin büyügü sabah namazından sonra birkaç gün üst üstüne hayvan pazarnna gider. Ev halkına yetecek münasip bir dana veyahut inek alır. Sürüden ayrlan hayvan, birinin gözetiminden eve getirilir. Kasaba haber edilir, randevu alınır ve hayvan kesilir. Kasap gövdeyi iri parçalara ayırarak oniki saat dinlenmeye brrakır. Kasap et donunca yamağı ile gelir, büyük bir örtü üzerindeki tahta alçak masaya geçer, Etin pastırmalık kısmını ayırır, kavurma, sucuk ve pasturma yapıllıdı(Yeğenoğlu, 2011, s. 38). Sonbahar gelir, soğuklar başlar. Kadının bağ çilesi dolmuștur. Zira şehirde ekmek pişirme derdi yoktur. Çünkü mahalle firnları vardır. Kuyudan su çekme işi yoktur, zira çeşmeler vardır. Aydınlatma işi çoğu yerlerde elektrik ile yapılmaktadır. Kadınlar şehre gelir, şehir evleri temizlenir, yerleştirilir, böylece bağ işi yeni bir bahara kalmıştır(Baydoğan, 2011).

Kayseri halkı için bağlar ve bağcılık büyük önem taşımıştr. Bağ yaşamı, toplumun yüzylllardır benimsediği, sevdiği ve kolay kolay vazgeçemeyeceği sosyal ve kültürel bir gelenek haline gelmiştir. $\mathrm{O}$ kadar ki, bazı Kayserililer "bağ" ile "bağlanma" filinin yakın ilişkide olduğunu, belki "bağ” sözcüğünün bağlanmaktan ve sevmekten geldiğini ifade etmiş, insanların bağlarnna bir tür gönül bağı ile bağı olduklarını belirtmişlerdir (İmamoğlu, 2001, s. 23)

\section{Kayseri'de Hamam Külttürü}

Kayseri’nin sahip olduğu ve bugün hala kullanımda olan hamamların büyük bir kısmı Selçuklular tarafindan inşa edilmiştir. Aşağıda adı geçen hamamlar Selçuklu, Osmanlı ve Türkiye Cumhuriyetinde Kayseri'de ikamet eden kişiler tarafindan kullanılmış ve zengin bir hamam kültürü 
gelişmiştir. Sosyal hayatın önemli bir parçası halini alan hamam, düğün-dernek gibi toplumsal faaliyetlerde önemli bir yer işgal etmiştir. Belli aralarda hamama gidilmiş, hamama gitme özellikle kadınlar için temizlenmenin yanı sıra sosyalleşme açıssından da önem arz etmiştir. Günün uzunca bir bölümü yıkanarak, eğlenerek, yemek yiyerek geçiren hanımlar aynca oğullarını evlendirecek olanlar, gelin adaylarııı rahatça gözlemleyebilmişlerdir.

\section{Sultan Hamamı:}

1205 ylında Selçuk hükümdarı Gıyaseddin Keyhüsrev I. tarafindan kız kardeşi Gevher Nesibe Sultan adına yaptrırlmıştır.

\section{Hunat Hamamı:}

1237 yilında Mahperi Hatun tarafindan yaptıılmıştır. Hunat Camii yanında.

\section{Gülük Hamamı:}

1334 ylında Gülük Şemseddin tarafindan yaptrılmıștır.

\section{Cafer Bey Hamamı:}

1151 ylında Erdanaoğullarından Cafer Bey tarafindan yaptırlmıştr.

\section{Kadı Hamamı:}

1548 yilında Kadı Bedreddin Mahmut tarafindan yaptrilmıştr.

\section{Selahattin Hamamı:}

1590 yilında yaptrıllmıştır. Kitabesi yok. Bu hamamdan Evliya Çelebi seyahatnamesinde bahseder(Çelebi, 1979, s. 76).

Hamama giderken Öncelikle, Bohça hazırlanır (çamaşır, havlu, nali, sabun, tarak, hamam tası, lif, kese vs...) sabahın erken saatlerinde kahvalt yapmadan hamama gidilir. Önce ylkanıllı; keselenilir, liflenilir, daha sonra dışarı çkkılır.

Evden gelen yiyecekler açıır (sucuk, pastırma, turşu, patates salatası vs.) bunlar yenilir, tekrar hamama girilir, ylkanılır, liflenilir, havluya sarılır hamamın içinden çıkılır, giyinilir, evden gelen eşyalar toplanır. Eve gidilir. Vakit akşama yaklaşmıştır.

Kayseri'de bulunan gayr-i Müslimler evlerinin yakınında olan Cafer Bey hamamına giderlerdi, diğerlerine gitmezlerdi. Çeşmede, sokakta çarşıda karşılaşıldığnnda hal hatır sorulur, konuşulurdu. Gayr-i Müslim bayan terzilere gidilir, kıyafet diktirilir; bayan kuaföre gidilir, saç bakımı yaptırlırdı(Baydoğan, 2011). 
Journal of Universal History Studies (JUHIS) • Vol. I • Issue 1 • 2018 • pp. 88-95

\section{Gelin Hamamı}

Gelin hamamına Salı günü gidilir. Kız tarafi hamamı kiralar, akraba ve ahbap evlerine önceden sabunlar dağttlır. Sabunların arkasında hamamın adının yazıldığı bir kâğıt yapıştıılır. Gelinin oturacağı yer döşenilir. Gençler gelinin yanına oturur. Kız tarafi hamama ev sahibesi olarak erken gider. Orada misafirlerini karşlar. Hamamda yapacağı ikramları kız tarafi götürür. Ayrıca hamamcıya temizlik yapan görevlilere hediyeler alını(Baydoğan, 2011). Kız hamama gelince gelinlik elbisesini giyip oturur. Biraz sonra natıra iki eline mumlar alır, arkasında da ikişer ikişer sıra olurlar ve aralarına gelini de alıp Erkilet Türküsünü okuyarak şadırvanın etrafinda dolanıllar. Bu sırada oğlan evi davetlilere para sepileri saçar(Barlas, 1963, s. 26).

Gelin kızı hamam kıyafetini giyer; ayağında gümüş nalisi, başında tacı hamama arkadaşlarıyla beraber girer, beraberlerinde tef, dümbelek çalıır, mumlar yakılır, şarkılar eşliğinde hamama girilir, önce hamamın içinde eğlence yapilır, daha sonra gelin kz hamamın yüksek bir yerine sandalye üzerine oturur; erkek tarafinın hanımları çeşitli hediyeler takar. Gelin ylkanır tekrar şenlik başlar, türküler eşliğinde gelin kız hamamdan çıkarlır. Büyüklerin elleri öpülür. Kız tarafindan getirilen yiyecekler misafirlere dağttllır. Böylece gelin hamamı sona erer, herkes evine gider (Baydoğan, 2011).

\section{Sonuç}

Kayseri, tarihi ipek yolunun önemli bir kolu üzerinde bulunmakla, dünya ile kesintisiz ilişkide bulunan, bütün zamanlarda önemli olmuş bir şehirdir. XIX. yüzylda bile tahıl ihtiyacını komşu şehirlerden sağlayan Kayseri'nin neden bir kültür, ticaret ve sanayi üssü olduğu kolayca anlaşlabilir. Kayseri'de bağcllk her zaman sosyal hayatın önemli bir unsuru olmuştur. Çeşitli sebeplerle ülkemizin çeşitli bölgelerinde beliren bağcllk ve bağa göçmeler arasında Kayseri bağcllı̆̆ıın, Kayseri şehri üzerine olan derin etkisi bakımından, gerçekten özel bir yeri vardır. Kayseri bağları, geniş ölçülü satış sağlayan yerler olmaktan çok, her ailenin kışlı bağ ürününü veren kaynaklar olarak göz önüne alınabilir. Kayseri'de yaz aylarında bağ göçlerinin ne zaman başlamış bulunduğu kesin olarak bilinememekle beraber, bağcilığın tarihinin, burada pek eski olduğu bilinen bir gerçektir. Bağlarn, Kayseri şehrinin ayrlamaz bir bütünleyicisi olduğu görülmektedir. Nitekim Kayserilinin bir ayağı şehirde, bir ayağı bağda olmuştur. Kayseri'de bağ hayatı geleneksel yaşayış biçiminden biri olmuş, Kayseri'nin sosyal hayatna renk ve güzellik katmıștr. 


\section{Kaynakça}

[1] Barlas, Halil Uğurol, Kayseri Düğünleri Üzerine Bir Araştırma Denemesi, Yurttaş Kitabevi Folklor Yayınları: 2, İstanbul 1963.

[2] Baydoğan, Mürüvet; 90 Yaşında, Kayseri doğumlu,"Mirat-i Kayseriyye” Yazarı Ahmet Nazif Efendinin Yiğeni, Kahveci Hakkı Ağa (Hakkı Baydoğan)'ın Kızı, Röportaj tarihi: 11.10.2011.

[3] Bozkurt, Ayşe; 70 Yaşında, Kayseri doğumlu, Röportaj tarihi: 15.09.2011.

[4] Çelebi, Ömer(1979). Kayseri ve Yöresinde Turizm, Yeni Matbaa, Kayseri.

[5] İmamoğlu, Vacit(2011). Kayseri Bağ Evleri, Türkiye İş Bankası Kültür Yayınlanı, Nisan 2001.

[6] İzbırak, Reşat(1947). “Kayseri Şehrinin İşleme ve Gelişmesinde Bağcılığın Etkileri”, Ankara Üniversitesi Dil ve Tarih-Coğrafya Fakültesi Dergisi, Cilt:5Sayı: 4 Ankara 1947. (401-414)

[7] Tali, Şerife(2008). Germir Evlerinin Giriş Kapı Tasarımları Üzerine Tipolojik Bir Araştırma, Sayı 21.

[8] Tali, Şerife(2005). “Geleneksel Kayseri Evlerinde Süsleme”, Ankara Üniversitesi Sosyal Bilimler Enstitüsü Dergisi, Cilt 6, Sayı 2.

[9] Ulusoy, Hatun; 65 Yaşında, Kayseri doğumlu, Röportaj tarihi: 15.09.2011.

[10] Yeğenoğlu, Mehmet Cavit(2011). Erciyes'den Püfür Püfür Eski Zamanlarda Kayseri Yaşam Kültürü, Kayseri İli Yardım Derneği İstanbul Şubesi Kültür Yayınları, İstanbul. 